\title{
DEVELOPMENT OF A CHINESE CHRONIC ILLNESS-RELATED STRESS INVENTORY FOR PRIMARY CARE
}

\author{
KAI-KUEN LEUNG,* BEE-HORNG LUE, *† \\ LI-YU TANG $\$$ and EN-CHANG WU§
}

\begin{abstract}
This study evaluates the construct validity and internal consistency of a Chronic IllnessRelated Stress Inventory (CRSI) for primary care Chinese patients and studies the relationship between chronic illness-related stress and sociodemographic characteristics and indices of disease severity. A total of 301 patients were interviewed using a structured questionnaire. The responses to the CRSI were divided into a frequency scale and a severity scale. Six factors including physical integrity and discomfort, psychosocial function and economic burdens, self-fulfillment and daily life, sexual function, self-esteem, and diet limitations were obtained for each CRSI scale. Except for the last factor, all other factors and the scale as a whole for both scales have a Cronbach $\alpha$ of $>0.90$. The results of the convergent and discriminant validity analysis were promising. In addition, chronic illness-related stress was related to insurance status and the self-perceived severity of disease. (C) 1999 Elsevier Science Inc.
\end{abstract}

Keywords: Chronic illness; Construct validity; Instrument; Primary care; Reliability; Stress.

\section{INTRODUCTION}

Chronic illnesses are a collection of various kinds of diseases of different etiologies, symptoms, disease courses, treatment strategies, and prognoses. They are difficult to define, but their common characteristics are incurability and long-term disability and dependency $[1,2]$. Being ill is considered threatening to most individuals. The stress perceived by patients with chronic illness is different from patients with acute illness. Patients with chronic illness are faced with long-standing conflicts, adjustments, and psychosocial situations to which they must adapt [3]. Moreover, these patients suffer from stress not only due to the demands of the illness, but also due to failure to cope with these demands [4].

In the literature, different investigators have emphasized different aspects of the chronic illness-related stress spectrum and have generated different chronic illnessrelated stress dimensions [3,5-8]. Although investigators classify chronic illnessrelated stress into different dimensions, the stress perceived by each patient is the result of interactions between himself and his intrapersonal systems, interpersonal

Departments of *Family Medicine and $†$ Social Medicine, College of Medicine, National Taiwan University, Taipei, Taiwan, ROC.

\$College of Nursing, Yang Ming University, Taipei, Taiwan, ROC.

$\S$ Department of Psychology, College of Science, National Taiwan University, Taipei, Taiwan, ROC.

Address correspondence to: Dr. Kai-Kuen Leung, Department of Family Medicine, National Taiwan University Hospital, No. 1 Chang-Te Street, Taipei 10016, Taiwan, ROC. Tel: 001-886-2-23970800 (ext. 6827); E-mail: kkleung@ha.mc.ntu.edu.tw 
relationships, and people in his social environment. Obviously, chronic disease stress would be best understood using a biopsychosocial paradigm. How patients perceive their illness is important to both clinicians and researchers. Lazarus proposed that the nature of the perceived stress is the most important determinant in the coping behaviors that people employ [9]. Because patients with chronic illness are exposed to long-term threat, how these patients deal with their stress has an important effect on outcome. According to many studies, individuals who experience more stress are likely to develop negative physical [10-12] and psychological responses [13-16]. Therefore, understanding chronic illness-related stress is the first step for a physician in helping patients to realize their problems, to use fruitful coping mechanisms, and to prevent detrimental consequences. In clinical practice, physicians usually spend very limited time with their chronically ill patients. In our society, people usually regard a primary care physician as someone who only takes care of physical conditions. Moreover, reporting psychosocial difficulties to others is considered shameful in Chinese culture, especially when done in a face-to-face manner. In the doctor-patient encounter, patients report only their physical discomfort and ask for symptomatic relief. Psychosocial issues and stress experiences are frequently not presented to physicians. Undiscovered stress may be related to poor medical compliance and adverse health outcome. To assess hidden stressors in chronic illness patients, an instrument that is theoretically sound, methodologically valid, and clinically applicable is needed. Unfortunately, most of the instruments available, such as the Social Readjustment Rating Scale [17] and the Hemodialysis Stressor Scale [18], are not designed for this purpose. Scales designed to measure illness-related stress in medical patients, such as the Meaning of Illness Questionnaire [19] and the Psychosocial Adjustment to Illness Scale [20], have not been validated empirically in Chinese patients treated by primary care physicians, and the usefulness of these instruments in primary care in our country is questionable.

This study was conducted for the purpose of designing a chronic illness-related stress questionnaire and to validate it in a group of primary care patients. The reliability and convergent and discriminant validity of this questionnaire are discussed.

\section{METHOD}

In this study, chronic illness is defined as any disease that is incurable, requires a prolonged period of medical care, and causes a slow decline in physical function. Most chronic diseases seen by primarycare physicians, such as hypertension, diabetic mellitus, and cerebral vascular accident, fulfill these criteria.

Patients who had chronic illnesses and had visited the family medicine out-patient clinic at the National Taiwan University Hospital for at least 6 consecutive months were candidates for this study. The 6-month interval was set to ensure that the patients were evaluated completely and the diagnosis of chronic illness was confirmed. Patients with a psychiatric diagnosis were excluded from this study because the kinds of stress they face and the way they respond to their difficulties are different from patients with chronic physical illness. All diagnostic information was confirmed by chart audit.

A total of 301 patients, each with at least one chronic illness, constituted the final sample. Their sociodemographic characteristics and diagnostic distribution are shown in Table I. After obtaining oral consent from the patients and their doctors, all patients were interviewed by a well-trained interviewer based on a structured questionnaire that included sociodemographic data, the CRSI, and questions about the duration and self-perceived severity of their chronic illnesses. Interviewer training included basic understanding of stress and illness, understanding the application of the CRSI, interview skills, and interview practice with simulated patients.

The chronic illness-related stress inventory (CRSI) is an instrument that was designed for this study. It has a multidimensional structure that captures different sources of illness-related stress. Ten illness- 
Table I.-Demographic characteristics of the study population

$$
(N=301)
$$

\begin{tabular}{|c|c|c|}
\hline Characteristics & No. & $\%$ \\
\hline \multicolumn{3}{|l|}{ Age } \\
\hline$<40 \mathrm{yr}$ & 14 & 4.7 \\
\hline $40-49 \mathrm{yr}$ & 34 & 11.3 \\
\hline $50-59 \mathrm{yr}$ & 84 & 27.9 \\
\hline $60-69 \mathrm{yr}$ & 128 & 42.5 \\
\hline $70-79 \mathrm{yr}$ & 38 & 12.6 \\
\hline$>79 \mathrm{yr}$ & 3 & 1.0 \\
\hline \multicolumn{3}{|l|}{ Gender } \\
\hline Male & 118 & 39.2 \\
\hline Female & 183 & 60.8 \\
\hline \multicolumn{3}{|l|}{ Education } \\
\hline None & 66 & 21.9 \\
\hline Elementary & 100 & 33.2 \\
\hline Junior high & 41 & 13.6 \\
\hline Senior high & 47 & 15.6 \\
\hline College & 47 & 15.6 \\
\hline \multicolumn{3}{|l|}{ Marital status } \\
\hline Married & 230 & 76.4 \\
\hline Never married & 9 & 3.0 \\
\hline Widowed/divorced & 62 & 20.6 \\
\hline \multicolumn{3}{|l|}{ Religious belief } \\
\hline None & 39 & 13.0 \\
\hline Taoism & 16 & 5.3 \\
\hline Buddhism & 117 & 38.9 \\
\hline Traditional & 80 & 26.6 \\
\hline Christian & 31 & 10.3 \\
\hline Others & 18 & 6.0 \\
\hline \multicolumn{3}{|l|}{ Insurance } \\
\hline None & 37 & 12.3 \\
\hline Labor & 216 & 71.8 \\
\hline Farmer & 33 & 11.0 \\
\hline Civil servant & 7 & 2.3 \\
\hline Others & 8 & 2.6 \\
\hline
\end{tabular}

related stress dimensions and a list of 110 stress-related items were developed by the investigators, based on a review of the literature and clinical experience. The ten dimensions were as follows: (a) physical discomfort caused by illness and treatment; (b) threats stemming from illness and treatment; (c) physical and functional changes; (d) deprivation of oral and sexual needs; (e) loss of self-esteem; (f) feeling of abnormality; (g) change in job and career; (h) economic burden; (i) change in social and family function; and (j) loss of self-control. The stress-related items were sent to four physicians and one clinical psychologist for content analysis. All five reviewers had experience in the treatment of chronically ill patients in primary care, and they also had research experience. Reviewers were asked to judge each item from the questionnaire as follows: (1) relevance to the dimension of stress that it is proposed to measure; (2) the impact of the stress item in terms of quality-of-life; and (3) the readability of the sentence. After the deletion of irrelevant items and the revision of some items, the questionnaire was tested by a group of 20 out-patients. A well-trained interviewer read all the questions to each of the patients and asked whether he (she) could understand the meaning of the items. Comments on each item were recorded and the questionnaire was again revised according to the comments of the patients. The final inventory contained 41 questions written in Chinese. An English translation of the CRSI is given in the Appendix. The response to each item was divided into two scales. The first scale captured the self-perceived frequency of each stress condition answered by a five-point Likert scale (always $=5$, often $=4$, sometimes $=3$, seldom $=2$, never $=1$ ) and the second scale captured the self-perceived severity of stress, answered by another five-point Likert scale (very severe $=5$, severe $=4$, moderate $=3$, mild $=2$, very mild $=1$ ). The total score of each scale was the sum of the raw score of the 41 items. The score of each subscale identified by factor analysis was the sum of the raw score of the item loading under each factor. 
The duration of chronic disease was defined as the total number of months a patient had acknowledged his (her) own chronic illness. If the patient had more than one chronic condition, the illness with the highest level of self-perceived severity and the longest duration was selected. The self-perceived severity of each chronic disease was answered by a five-point Likert scale (very severe, severe, moderate, mild, very mild). A self-perceived severity score was calculated from the sum of the severity score of all acknowledged chronic illnesses.

Factor analysis using the principle components method was applied to the frequency scale and the severity scale of the CRSI. A varimax rotation was selected because we hypothesized that factors identified in the CRSI may be correlated. Cronbach $\alpha$ analysis was applied to both scales to examine the itemtotal correlation of each item of the inventory and the internal consistency of the whole scale. Convergent and discriminant validity were examined by comparing the frequency and severity scale of the CRSI. Convergent validity was defined as high correlation between measures of the frequency scale and the severity scale on the same factor. Discriminant validity was assessed as follows: (1) correlations between measures of different factors of the same scale should be less than the correlations between measures of the same factor of different scales; (2) correlations between measures of different factors of different scales should be less than the correlations between measures of the same factor of different scales; and (3) a similar pattern of interrelation between factors should be seen in both scales.

The relationships between sociodemographic characteristics including gender, educational level, marital status, religious belief, and insurance status and the CRSI were examined by ANOVA. The relationships between continuous variables including age, number of chronic illnesses, total score of self-perceived severity of illnesses, and duration of chronic illness and the CRSI were examined by the Pearson product-moment correlation.

\section{RESULTS}

\section{Reliability measures}

Factor analysis and internal consistency of the frequency scale of the CRSI. Nine factors were extracted with an eigenvalue of $>1$. This explained $73.8 \%$ of the total variance. All items clustered under each factor had factor loading of $>0.40$, but there were three factors with only two items. To reduce the number of factors and make the results easier to interpret, a six-factor model was chosen by referring to the slope of the scree test. The six factor model explained $64.9 \%$ of the total variance. Internal consistency of items under each factor and all items of the whole questionnaire were calculated by using Cronbach $\alpha$ statistic [21]. The results of the factor analysis and Cronbach $\alpha \mathrm{s}$ are shown in Table II. Factor 1 (physical integrity and discomfort) contains 12 items regarding physical discomfort caused by chronic illness and treatment. It also contains items about threats to bodily integrity and health. Factor 2 (psychosocial function and economic burden) contains nine items regarding change of psychosocial roles and function and economic burdens due to illness and treatment. Factor 3 (self-fulfillment and daily life) contains nine items regarding achievements, change of physical appearance, ability to perform usual activities, and ability to work. Factor 4 (sexual function) contains four items about sexual problems stemming from chronic illness. Factor 5 (self-esteem) contains three items regarding loss of self-esteem and the social stigma of chronic illness. Cronbach $\alpha$ s of the first five factors were $>0.90$. Factor 6 (diet limitations) contains four items, two related to limitation of diet and two items unrelated to diet. The Cronbach $\alpha$ of the items of the sixth factor was 0.50 , implying that these items were not highly related. The Cronbach $\alpha$ became 0.86 if the last two items were excluded. The Cronbach $\alpha$ of the whole scale was 0.94 .

Factor analysis and internal consistency of the severity scale of the CRSI. Factor analysis of the severity scale also produced nine factors with an eigenvalue of $>1$, which explained $77.4 \%$ of the total variance. Like the factor structure of the fre- 
Table II.-Factor analysis and internal consistency of the frequency scale of the chronic illness-related stress inventory

\begin{tabular}{|c|c|c|c|c|c|c|}
\hline Items & Factor 1 & Factor 2 & Factor 3 & Factor 4 & Factor 5 & Factor 6 \\
\hline 2. Illness symptoms & 0.82 & - & - & - & - & - \\
\hline 1. Physical discomfort & 0.82 & - & - & - & - & - \\
\hline 3. Worry pain & 0.80 & - & - & - & - & - \\
\hline 10. Worry discomfort & 0.79 & - & - & - & - & - \\
\hline 8. Loss of control & 0.76 & - & - & - & - & - \\
\hline 9. Unexpected health & 0.72 & - & - & - & - & - \\
\hline 4. Unrelieved symptom & 0.71 & - & - & - & - & - \\
\hline 6. Health decline & 0.68 & - & - & - & - & - \\
\hline 5. Feel sick & 0.64 & - & - & - & - & - \\
\hline 7. Worry about death & 0.63 & - & - & - & - & - \\
\hline 11. Weak and feeble & 0.46 & - & - & - & - & - \\
\hline 27. Treatment discomfort & 0.44 & - & - & - & - & - \\
\hline 35. Unfulfilled family roles & - & 0.75 & - & - & - & - \\
\hline 33. Loss of job & - & 0.73 & - & - & - & - \\
\hline 32. Economic problems & - & 0.72 & - & - & - & - \\
\hline 30. Dependency & - & 0.71 & - & - & - & - \\
\hline 31. Useless person & - & 0.70 & - & - & - & - \\
\hline 36. Loss of social life & - & 0.66 & - & - & - & - \\
\hline 37. Limited social contact & - & 0.65 & - & - & - & - \\
\hline 29. Economic burden & - & 0.64 & - & - & - & - \\
\hline 34. Family relationships & - & 0.62 & - & - & - & - \\
\hline 18. Disruption of career & - & - & 0.79 & - & - & - \\
\hline 16. Disruption of life plan & - & - & 0.77 & - & - & - \\
\hline 15. Disruption of will & - & - & 0.74 & - & - & - \\
\hline 17. Can't do as wanted & - & - & 0.72 & - & - & - \\
\hline 26. Unable to work & - & - & 0.60 & - & - & - \\
\hline 14. Restricted activities & - & - & 0.60 & - & - & - \\
\hline 28. Family routine & - & - & 0.46 & - & - & - \\
\hline 13. Worry about appearance & - & - & 0.43 & - & - & - \\
\hline 12. Change appearance & - & - & 0.41 & - & - & - \\
\hline 23. Sexual activity & - & - & - & 0.92 & - & - \\
\hline 22. Sexual desire & - & - & - & 0.91 & - & - \\
\hline 24. Sexual life & - & - & - & 0.90 & - & - \\
\hline 21. Sexual ability & - & - & - & 0.90 & - & - \\
\hline 39. Hide illness & - & - & - & - & 0.93 & - \\
\hline 41. Feel shame & - & - & - & - & 0.90 & - \\
\hline 38. Illness known by others & - & - & - & - & 0.87 & - \\
\hline 19. Can't enjoy food & - & - & - & - & - & 0.85 \\
\hline 20. Diet control & - & - & - & - & - & 0.83 \\
\hline 40. Sick person & - & - & - & - & - & 0.40 \\
\hline 25. Worry side-effect & - & - & - & - & - & 0.29 \\
\hline Cronbach's $\alpha$, total $=0.94$ & 0.93 & 0.90 & 0.90 & 0.99 & 0.92 & 0.50 \\
\hline
\end{tabular}

quency scale, the severity scale could be simplified by a six-factor model, which explained $69 \%$ of the total variance. Table III presents the results of the factor analysis and internal consistency of the severity scale. Factors 1 and 4 contain the same items as the frequency scale. The other factors had items similar to the factor structure of the frequency scale. The items of the first four factors had a Cronbach $\alpha$ of $>0.90$. The last two factors had a Cronbach $\alpha$ of 0.75 and 0.76 , respectively. The Cronbach $\alpha$ of the whole scale was 0.95 .

Convergent and discriminant validity of the CRSI. The correlation coefficient of the two scales was high $(r=0.90)$. This implies that these two scales were highly cor- 
Table III.-Factor analysis and internal consistency of the severity scale of chronic illness-related stress inventory

\begin{tabular}{|c|c|c|c|c|c|c|}
\hline Items & Factor 1 & Factor 2 & Factor 3 & Factor 4 & Factor 5 & Factor 6 \\
\hline 3. Worry pain & 0.83 & - & - & - & - & - \\
\hline 2. Illness symptoms & 0.82 & - & - & - & - & - \\
\hline 4. Unrelieved symptom & 0.82 & - & - & - & - & - \\
\hline 10. Worry discomfort & 0.81 & - & - & - & - & - \\
\hline 1. Physical discomfort & 0.80 & - & - & - & - & - \\
\hline 8. Loss of control & 0.80 & - & - & - & - & - \\
\hline 9. Unexpected health & 0.79 & - & - & - & - & - \\
\hline 5. Feel sick & 0.73 & - & - & - & - & - \\
\hline 6. Health decline & 0.71 & - & - & - & - & - \\
\hline 7. Worry about death & 0.66 & - & - & - & - & - \\
\hline 27. Treatment discomfort & 0.55 & - & - & - & - & - \\
\hline 11. Weak and feeble & 0.49 & - & - & - & - & - \\
\hline 30. Dependency & - & 0.80 & - & - & - & - \\
\hline 33. Loss of job & - & 0.78 & - & - & - & - \\
\hline 32. Economic problems & - & 0.76 & - & - & - & - \\
\hline 29. Economic burden & - & 0.74 & - & - & - & - \\
\hline 35. Unfulfilled family roles & - & 0.74 & - & - & - & - \\
\hline 31. Useless person & - & 0.63 & - & - & - & - \\
\hline 36. Restricted social life & - & 0.60 & - & - & - & - \\
\hline 37. Limited social contact & - & 0.59 & - & - & - & - \\
\hline 34. Family relationships & - & 0.59 & - & - & - & - \\
\hline 28. Family routine & - & 0.48 & - & - & - & - \\
\hline 16. Disruption of life plan & - & - & 0.84 & - & - & - \\
\hline 18. Disruption of career & - & - & 0.82 & - & - & - \\
\hline 15. Disruption of will & - & - & 0.81 & - & - & - \\
\hline 17. Can't do as wanted & - & - & 0.74 & - & - & - \\
\hline 14. Restricted activities & - & - & 0.67 & - & - & - \\
\hline 26. Unable to work & - & - & 0.44 & - & - & - \\
\hline 13. Worry about appearance & - & - & 0.38 & - & - & - \\
\hline 23. Sexual activity & - & - & - & 0.94 & - & - \\
\hline 22. Sexual desire & - & - & - & 0.94 & - & - \\
\hline 21. Sexual ability & - & - & - & 0.93 & - & - \\
\hline 24. Sexual life & - & - & - & 0.91 & - & - \\
\hline 39. Hide illness & - & - & - & - & 0.92 & - \\
\hline 41. Feel shame & - & - & - & - & 0.89 & - \\
\hline 38. Illness known by others & - & - & - & - & 0.86 & - \\
\hline 40. Sick person & - & - & - & - & 0.52 & - \\
\hline 25. Worry side-effect & - & - & - & - & 0.28 & - \\
\hline 19. Can't enjoy food & - & - & - & - & - & 0.83 \\
\hline 20. Diet control & - & - & - & - & - & 0.78 \\
\hline 12. Change appearance & - & - & - & - & - & 0.37 \\
\hline Cronbach's $\alpha$, total $=0.95$ & 0.94 & 0.92 & 0.90 & 0.99 & 0.75 & 0.76 \\
\hline
\end{tabular}

related with each other. Table IV presents the zero-order correlation matrix between different factors derived from factor analysis of the two scales. Corresponding factors of the two scales had a correlation coefficient of $>0.80$ for the first five factors and a correlation coefficient of 0.43 for the last factor. The average coefficient for convergent validity was 0.80 . The average coefficients among different factors measured by the same scale and across different scales were 0.36 and 0.35 , respectively. In Table IV, a similar pattern of interrelation between factors is shown. In each scale, the correlation is higher among the first three factors than the last 
Table IV.-Correlation matrix of the factors of the frequency and severity scales ${ }^{\mathrm{a}}$

\begin{tabular}{|c|c|c|c|c|c|c|c|c|c|c|c|c|}
\hline $\begin{array}{l}\text { Scale } \\
\text { factor }\end{array}$ & $\begin{array}{l}1 \\
1\end{array}$ & 2 & 3 & 4 & 5 & 6 & $\begin{array}{l}2 \\
1\end{array}$ & 2 & 3 & 4 & 5 & 6 \\
\hline 11 & 1.00 & & & & & & & & & & & \\
\hline 2 & 0.55 & 1.00 & & & & & & & & & & \\
\hline 3 & 0.66 & 0.65 & 1.00 & & & & & & & & & \\
\hline 4 & 0.37 & 0.44 & 0.53 & 1.00 & & & & & & & & \\
\hline 5 & 0.19 & 0.33 & 0.30 & 0.15 & 1.00 & & & & & & & \\
\hline 6 & 0.05 & 0.12 & 0.13 & 0.17 & 0.10 & 1.00 & & & & & & \\
\hline 21 & 0.89 & 0.50 & 0.55 & 0.26 & 0.20 & 0.06 & 1.00 & & & & & \\
\hline 2 & 0.60 & 0.91 & 0.65 & 0.43 & 0.35 & 0.10 & 0.59 & 1.00 & & & & \\
\hline 3 & 0.57 & 0.55 & 0.83 & 0.41 & 0.31 & 0.18 & 0.62 & 0.60 & 1.00 & & & \\
\hline 4 & 0.37 & 0.39 & 0.48 & 0.88 & 0.20 & 0.21 & 0.27 & 0.41 & 0.38 & 1.00 & & \\
\hline 5 & 0.27 & 0.31 & 0.35 & 0.25 & 0.83 & 0.37 & 0.30 & 0.36 & 0.39 & 0.28 & 1.00 & \\
\hline 6 & 0.41 & 0.41 & 0.38 & 0.26 & 0.14 & 0.43 & 0.46 & 0.38 & 0.39 & 0.27 & 0.26 & 1.00 \\
\hline
\end{tabular}

${ }^{a}$ Scale 1, frequency scale; scale 2, severity scale. Factor 1, physical integrity; factor 2, psychosocial function; factor 3 , self-fulfillment; factor 4, sexual function; factor 5, self-esteem; factor 6 , diet limitation.

three factors and there is a trend toward a decrease in coefficients from top to bottom and from left to right in the correlation matrix.

Relationship between sociodemographic characteristics and chronic illness-related stress. Age, gender, marital status, and religious belief were statistically unrelated to each of the two scales of the chronic illness-related stress inventory. Insurance status was the only variable statistically related to the whole and to many factors of both scales (Table V). This result indicates that patients without medical insurance coverage perceived more illness-related stress than those with insurance coverage. Moreover, the perceived stress included not only financial burdens but physical burdens as well.

Relationship between number, duration, and perceived severity of disease and chronic illness-related stress. Table VI presents the correlation matrix of the three

Table V.-Relationship between insurance status and the frequency and severity scale of the CRSI

\begin{tabular}{lrc}
\hline Scale and factor & $F$-value & $p$-Value \\
\hline Frequency & 15.27 & 0.0001 \\
Physical integrity & 10.60 & 0.0013 \\
Psychosocial function & 55.20 & $<0.0001$ \\
Self-fulfillment & 2.57 & $\mathrm{NS}^{\mathrm{a}}$ \\
Sexual function & 1.04 & $\mathrm{NS}$ \\
Self-esteem & 0.76 & $\mathrm{NS}$ \\
Diet limitation & 0.01 & $\mathrm{NS}$ \\
Severity & 12.60 & 0.0005 \\
Physical integrity & 8.65 & 0.0035 \\
Psychosocial function & 47.71 & $<0.0001$ \\
Self-fulfillment & 1.04 & $\mathrm{NS}$ \\
Sexual function & 2.10 & $\mathrm{NS}$ \\
Self-esteem & 0.00 & $\mathrm{NS}$ \\
Diet limitation & 7.34 & 0.0071 \\
\hline
\end{tabular}

aNonsignificant. 
Table VI.-Correlation matrix of three disease characteristics and chronic illness-related stress

\begin{tabular}{lccccccc}
\hline $\begin{array}{l}\text { Scale } \\
\text { factor }\end{array}$ & 1 & 1 & 2 & 3 & 4 & 5 & 6 \\
\hline NUM & $0.17^{\mathrm{a}}$ & 0.15 & 0.12 & 0.11 & $0.18^{\mathrm{a}}$ & 0.01 & 0.15 \\
SEV & $0.37^{\mathrm{b}}$ & $0.33^{\mathrm{b}}$ & $0.30^{\mathrm{b}}$ & $0.27^{\mathrm{b}}$ & $0.28^{\mathrm{b}}$ & 0.09 & $0.19^{\mathrm{a}}$ \\
DUR & 0.16 & 0.12 & 0.14 & 0.08 & $0.20^{\mathrm{a}}$ & 0.04 & $0.18^{\mathrm{a}}$ \\
Scale & & & & & & & \\
factor & 2 & 1 & 2 & 3 & 4 & 5 & 6 \\
\hline NUM & 0.15 & 0.11 & 0.14 & 0.09 & $0.23^{\mathrm{b}}$ & 0.12 & 0.15 \\
SEV & $0.37^{\mathrm{b}}$ & $0.29^{\mathrm{b}}$ & $0.34^{\mathrm{b}}$ & $0.25^{\mathrm{b}}$ & $0.33^{\mathrm{b}}$ & 0.10 & $0.28^{\mathrm{b}}$ \\
DUR & 0.16 & 0.08 & $0.17^{\mathrm{a}}$ & 0.06 & $0.28^{\mathrm{b}}$ & 0.04 & $0.19^{\mathrm{a}}$ \\
\hline
\end{tabular}

Scale 1, frequency scale; scale 2, severity scale. Factor 1, physical integrity; factor 2, psychosocial function; factor 3, self-fulfillment; factor 4, sexual function; factor 5, self-esteem; factor 6, diet limitation; NUM, number of chronic illnesses; SEV, self-perceived stress; DUR, duration of illness.

${ }^{\mathrm{a}} p<0.01 ;{ }^{\mathrm{b}} p<0.001$.

disease characteristics and measures of the frequency and severity scale. Number and duration of disease were weakly related to factor 4 (sexual function) in both scales. The self-perceived severity of disease was strongly related to both scales and most of the factors, indicating that those who interpreted their diseases as more severe at the same time perceived more illness-related stress.

\section{DISCUSSION}

Hypertension, diabetes mellitus, cerebrovascular disease, cardiovascular disease, and arthritis are the most common chronic conditions encountered in primary practice in Taiwan. Patients with different kinds of chronic illness may have some types of stress in common and some stress related only to the specific disease. In the process of composing illness-related stress items, only items that targeted stress related to most types of disease were included in this inventory. Although ten different dimensions were proposed to construct the inventory, only 41 items that described stress conditions frequently encountered in primary care were selected. The results of the factor analysis were promising. Nine factors were produced in the initial analysis for both the frequency and severity scales. These nine factors empirically reproduced nearly all the proposed dimensions of illness-related stresses. The shortcomings of the nine-factor model were that many factors contained only two items, and that further analysis was too complicated. One way to solve this problem would be to add more items to those factors with too-few items. However, this lengthens response time and makes it less practical to use in a primary care setting. Moreover, the scree test revealed that there was a break-point on the slope at the sixth factor, so a six-factor model seemed to be more appropriate. A six-factor model gave a satisfactory item separation and explained $>60 \%$ of the total variance of the sample. With only a few exceptions, factor analyses of frequency and severity produced factors containing identical items.

Internal consistency reliability of the CRSI was tested by Cronbach $\alpha$ analysis. When compared with other indicators of reliability measures, Cronbach $\alpha$ gave a 
lower bound for the reliability of multi-item scales [22]. Our results revealed very high internal consistency among items of the instrument as a whole and across different factors as identified by factor analysis. The only exception was the last factor. It contained items about diet limitation and two further items not related to diet. These two items had very low factor loading compared with items concerned with diet limitation. Further study may focus on revision or deletion of items that had low item-total correlations within each factor to maximize the Cronbach $\alpha$ value. Diet problems seemed to be a unique component in illness-related stress in our study population. Because hypertension, diabetes mellitus, cerebrovascular disease, and cardiovascular disease made up the majority of our sample, it was not surprising that these patients perceived considerable stress stemming from diet restriction.

Conventionally, construct validity is examined by the multitrait-multimethod (MTMM) technique, originally described by Campbell and Fiske [23]. However, MTMM methodology requires comparison of different traits with different methods. In our experience, we had difficulty finding other well-established tests to measure chronic illness stress in Chinese patients. With these limitations, we examined the convergent and discriminant ability of the CRSI with the two response scales. This approach may be less convincing than the original MTMM design from a methodological point of view, but is more feasible to carry out in a early study.

In the present investigation, the correlation matrix revealed high correlation coefficients between different scales of the same factor for the first five factors, but was obviously low for the last factor. This finding was consistent with the results of factor analysis and Cronbach $\alpha$ analysis, where the measures of the last factor in both scales contained more nonidentical items and lower internal consistency among items. Measurement of the last factor for the two scales might imply different stress dimensions. Except for the items comprising the last factor, it was demonstrated that the CRSI had fulfilled the basic requirement of construct validity.

Chronic illness-related stress correlated with insurance status, but not with other sociodemographic characteristics such as age, gender, marital status, education level, and religious belief. This demonstrates that the financial burden from a chronic, never-ending condition was a very important stressor for patients. It was noteworthy that patients without medical insurance had stress other than financial burdens. Physical burden was also higher in patients without medical insurance than in those with insurance coverage. An explanation could not be obtained from the results of this study. It is possible that there was a substantial difference between patients with insurance coverage and those without coverage who sought medical care. Medical insurance is a well-known variable that can affect one's illness behavior [24-26].

Chronic illness-related stress was also moderately correlated with the self-perceived severity of illness. The relation between illness-related stress and the objective characteristics of illness, including the number of chronic illnesses and the duration of the most severe illness, was markedly low. It is possible that an individual may use similar information in the cognitive evaluation of illness-related stress and severity of illness. The cognitive process, not the objective nature of the illness, was shown to be more important in the formation of stress. This result is concordant with most results described in the literature reporting that cognitive appraisal is important in determining the stress of an event [27-29].

Clinical applicability is a major concern in the development of measurement in- 
struments. The CRSI was developed to assist clinicians in identifying hidden stresses and improving the quality of care. Completing the CRSI (including the frequency and severity scales) requires an average of 10 minutes. Self-rating of the CRSI may require less time to complete. There is no test similar to the SMOG grading formula to test the readability of the questionnaire in the Chinese language. In the development of the CRSI, items were written in simple sentences with plain vocabulary, so that the questionnaire could be understood by people with 6 years of education.

This study showed that the CRSI is a promising instrument for the evaluation of chronic illness-related stress in a primary care setting in the Chinese population. Further improvement of the CRSI should focus on item selection and revision, especially items in the last factor. Reliability and validity studies should be continued with other methods and in other samples. In future studies, we will need to prove whether the CRSI can predict clinical outcomes. This is a major concern for clinicians who use an instrument to measure stress in chronic illness.

\section{REFERENCES}

1. Curtin M, Lubkin I. What is chronicity? In: Lubkin IM, ed. Chronic illness: impact and interventions, 2nd ed. Boston: Jones and Bartlett 1990:2-20.

2. Dimond M, Jones SL. Chronic illness across the life span. Norwalk, Connecticut: Appleton-CenturyCrofts 1983.

3. Abram HS. The psychology of chronic illness. J Chronic Dis 1972;25:659-641.

4. Ben-Sira Z. Chronic illness,stress and coping. Soc Sci Med 1984;18:725-736.

5. Levy N. The chronically ill patient. Psychiatry Q 1979;51:189-197.

6. Moos RH, Tsu VD. The crisis of physical illness: an overview. In: Moos RH, ed. Coping with physical illness. New York: Plenum 1977:3-21.

7. Miller JF. Coping with chronic illness. In: Miller JF, ed. Coping with chronic illness: overcoming powerlessness. Philadelphia: Lippincott 1983:15-36.

8. Cohen F, Lazarus RS. Coping with stresses of illness. In: Stone GC, Cohen F, Adler NE, eds. Health psychology. San Francisco: Jossey-Bass 1979:217-254.

9. Lazarus RS, Launiar R. Stress-related transactions between person and environment. In: Pervin LA, Levis M, eds. Perspectives in interactional psychology. New York: Plenum 1978:287-327.

10. Krantz DS. Cognitive processes and recovery from heart attack: a review and theoretical analysis. J Human Stress 1980;6:27-38.

11. Harrell JP. Psychological factors and hypertension: a status report. Psychol Bull 1980;87:482-501.

12. Cohen F. Personality, stress and the development of physical illness. In: Stone GC, Cohen F, Alder NE, eds. Health psychology — a handbook. San Francisco: Jossey-Bass 1979.

13. Paykel ES. Life stress and psychiatric disorder: applications of the clinical approach. In: Dohrenwend BS, Dohrenwend BP, eds. Stressful life events: their nature and effect. New York: Wiley 1974:135-149.

14. Theorell T. Selected illness and somatic factors in relation to two psychosocial stress indices: a prospective study in middle-aged construction building workers. J Psychosom Res 1976;20:17-20.

15. McCabe PM, Schneiderman N. Psychophysiologic reactions to stress. In: Schneiderman N, Tapp J, eds. Behavioural medicine. Hillsdale, New Jersey: Erlbaum 1985.

16. Turner RJ, Beiser M. Major depression and depressive symptomatology among the physically disabled: assessing the role of chronic stress. J Nerv Ment Dis 1990;178:343-350.

17. Holmes TH, Rahe RH. The social readjustment rating scale. J Psychosom Res 1967;11:213-218.

18. Baldree KS, Murphy SR, Powers MJ. Stress identification and coping patterns in patients on hemodialysis. Nurs Res 1982;31:107-112.

19. McAdams C, Byrne C, Browne G, Roberts J, Streiner D. Measuring the meaning of illness in cancer patients. Paper presented at the Fourth National Symposium on Oncology Nursing, McMaster University, Hamilton, ON, Canada.

20. Derogatis LR. The psychosocial adjustment to illness scale (PAIS). J Psychosom Res 1986;30:77-91.

21. Cronbach, LJ. Coefficient alpha and the internal structure of tests. Psychometrika 1951;16:297-334. 
22. Novick M, Lewis G. Coefficient alpha and the reliability of composite measurements. Psychometrika 1967;32:1-13.

23. Campbell DT, Fiske DW. Convergent and discriminant validation by the multitrait-multimethod matrix. Psychol Bull 1959;56:85-105.

24. Aday LA, Lee ES, Spears B, et al. Health insurance and utilization of medical care for children with special health care needs. Med Care 1993;31:1013-1026.

25. Landerman LR, Burns BJ, Swartz MS, et al. The relationship between insurance coverage and psychiatric disorder in predicting use of mental health services. Am J Psychiatry 1994;151:1785-1790.

26. Brindis C, Kapphahn C, McCarter V, Wolfe AL. The impact of health insurance status on adolescents' utilization of school-based clinic services: implications for health care reform. J Adolesc Health 1995;16:18-25.

27. Lazarus RS, Folkman S. Stress, appraisal, and coping. New York: Springer 1984.

28. Lazarus RS, Launier R. Stress-related transactions between person and environment. In: Pervin LA, Lewis M, eds. Perspectives in interactional psychology. New York: Plenum 1978.

29. Cohen F, Lazarus RS: Coping and adaptation in health and illness. In: Mechanic D, ed. Handbook of health, health care, and health professions. New York: Free Press 1983.

\section{APPENDIX A}

English translation of the CRSI domains and items:

(a) Physical discomfort caused by illness and treatment (four items):

1. I physically feel discomfort all the time due to chronic illness

2. I suffer from symptoms caused by chronic illness

4. I cannot get rid of those symptoms caused by my illness

27. I suffer from discomfort caused by the treatment

(b) Threats stemming from illness and treatment (six items):

3. I worry that chronic illness will bring about pain and discomfort

6. I worry about the deterioration of my health

7. I worry that I am going to die of my illness

10. I worry that I must live with my illness and discomfort for a long period of time

13. I worry that illness will change my physical appearance

25. I worry about treatment side effects

(c) Physical and functional changes (four items):

14. I cannot continue my usual activities after being ill

30. I have to depend on others after being ill

11. I have become weak and feeble

26. I cannot continue my work after being ill

(d) Deprivation of oral and sexual needs (six items):

19. I cannot enjoy my favorite foods due to my illness

20. I must control my diet due to illness

21. I lost sexual desire due to illness

22. I have to limit my sexual activity due to illness

23. My sexual ability declined due to illness

24. Treatment of my illness affects my sexual life

(e) Loss of self-esteem (four items):

38. I do not want others to know that I am chronically ill

39. I hide my illness from others

40. I do not like others to treat me as a sick person

41. I feel shame at having a chronic illness

(f) Feeling of abnormality (three items):

5. I feel that I will always be a sick person

12. Chronic illness changed my physical appearance

31. I became a useless person after being ill

(g) Change of job and career (six items):

15. Being chronically ill prevents me from achieving my will 
16. My illness affects my life plan

17. Being chronically ill prevents me from doing what I want to do

18. Being chronically ill prevents the development of my career

26. Treatment of my illness disrupts my usual working schedule

33. I cannot continue my job after being ill

(h) Economic burden (two items):

29. Treatment of my illness increases my economic burden

32. I have economic difficulties after being ill

(i) Change in social and family function (five items):

28. Treatment of my illness disrupts my family routine

34. Being chronically ill affects the relationship between me and my family

35. I cannot fulfill my family responsibilities (such as earn money, do housework, etc.) after being ill

36. I cannot continue my usual social activities because of my illness

37. I have to limit my time in social interactions after being ill

(j) Loss of self-control (two items):

8. I cannot control the progression of my illness

9. I cannot anticipate the deterioration of my illness 